\title{
Uso de plataformas on line para o ensino de Geografia: Lapig Maps
}

\section{Uso de plataformas on line para la enseñanza de Geografía: Lapig Maps}

\section{Use of online platforms for Geography education: Lapig Maps}

\author{
Elaine Barbosa da Silva \\ elainesilvaufg@gmail.com \\ Universidade Federal de Goiás, UFG/Instituto de Estudos Socioambientais, IESA, Goiânia, GO \\ Rodrigo Lima Santos \\ rlimasantos3@gmail.com \\ Universidade Federal de Goiás, UFG/Instituto de Estudos Socioambientais, IESA, Goiânia, GO \\ Vanilton Camilo de Souza \\ souzavanilton@gmail.com \\ Universidade Federal de Goiás, UFG/Instituto de Estudos Socioambientais, IESA, Goiânia, GO \\ Alex Mota dos Santos \\ alex.geotecnologias@gmail.com \\ Universidade Federal de Goiás, UFG, Goiânia, GO
}

Resumo: Com a ampla disseminação da informação geográfica por meio dos Sistemas de Informação Geográfica on line (SIG) é possível realizar diversas análises espaciais de forma rápida e interativa. Embora essa possibilidade seja fundamental para o aprimoramento do ensino de Geografia, essas plataformas ainda têm sido pouco exploradas na sala de aula. Neste artigo apresenta-se a plataforma do portal LAPIG Maps como ferramenta para o desenvolvimento de atividades interativas no ensino de Geografia. Discute-se seu potencial como importante ferramenta auxiliar no desenvolvimento teórico-prático dos conteúdos, associados às categorias geográficas de análise.

Palavras-chave: Geotecnologia, dados geográficos, ferramentas para ensino.

Resumen: Con la amplia difusión de la información geográfica a través de los Sistemas de Información Geográfica on line (SIG) es posible hacer diversos análisis espaciales de forma rápida e interactiva. Aunque esta posibilidad es fundamental para el perfeccionamiento de la enseñanza de Geografía, estas plataformas todavía han sido poco exploradas en el aula. En este artículo se presenta la plataforma del portal LAPIG Maps como herramienta para el desarrollo de actividades interactivas para la enseñanza de Geografía. Discutiese su potencial como herramienta auxiliar al desarrollo teórico-práctico de los contenidos, asociados a las categorías geográficas de análisis.

Palabras-Clave: Geotecnología, datos geográficos, herramientas de enseñanza. 
Abstract: Along with the wide dissemination of geographic information through online Geographic Information Systems (GIS), it is possible to do several spatial analyzes in a quick and interactive way. Although this possibility appears fundamental for the improvement of geography teaching, these platforms have still been little explored in the classroom. In this paper, we present the LAPIG Maps platform as a tool for the development of interactive activities for the teaching of Geography. We discuss its potential as an important auxiliary tool in the theoretical-practical development of the contents, associated with the geographic categories of analysis

Key words: Geotechnology, geographic data, teaching tools.

\section{INTRODUÇÃO}

A Ciência da Informação Geográfica é composta pelo conjunto dos domínios de conhecimentos que envolvem a produção e a utilização de informação geográfica georreferenciada. Em sua conjuntura, a Ciência da Informação Geográfica abrange como principais áreas de conhecimento a Cartografia, os Sistemas de Posicionamento Global, o Sensoriamento Remoto, os Sistema de Informação Geográfica e envolve ainda conhecimentos de estatística e de programação. Essa amplitude de conhecimento constitui as Geotecnologias.

Desta forma, ficou mais fácil e rápido compreender o espaço geográfico havendo a disponibilidade de diversos ambientes computacionais num Sistema de Informações Geográficas (SIG), onde é possível acessar e manipular informações geográficas diversas on line. Todo esse aparato tecnológico desenvolveu-se de forma rápida e encontra-se em um processo continuo de evolução. Atualmente é possível ter acesso a informação geográfica de vários lugares do mundo e correlacioná-las no tempo e no espaço, facilitando assim o ensino de geografia (SILVA; RODRIGUEZ, 2014).

Dentre as plataformas existentes em ambiente SIG destacam-se Google Earth, IBGE Teen, IBGE Kids, Água em Jogo, SIEG-Mapa Interativo e o LAPIG Maps. Essas plataformas permitem ao professor aprimorar as técnicas de aprendizagem ao trabalhar on line com geotecnologias junto com seus alunos. No entanto, a utilização cotidiana destes ambientes pelos professores de Geografia ou de áreas que utilizam a informação geográfica tem sido limitada. Diante de tamanha abrangência de informação faz-se necessário um redirecionamento no ensino de Geografia para que este consiga integrar em seu objeto de estudo e concepções metodológicas os avanços tecnológicos (FITZ, 2008a, 2008b, 2010).

Neste contexto, o presente trabalho tem como objetivo apresentar a Plataforma LAPIG Maps, desenvolvida pelo Laboratório de Processamento de Imagens e Geoprocessamento da Universidade Federal de Goiás (LAPIG - UFGO), na qual encontram-se mais de 8 mil camadas de dados geográficos de fácil acesso, tanto para aquisição quanto para manipulação on line de seus conteúdos (CASTRO; FERREIRA, 2012). Trata-se de uma opção robusta para o desenvolvimento de atividades geográficas, em seus vários aspectos (SILVA et al., 2017), e assim contribuir tanto para a formação de professores, quanto para a disseminação de práticas educativas interativas. 


\section{‘TECNOLOGIAS-GEO’ APLICADAS AO ENSINO}

A integração das tecnologias na educação é tema de estudo de diversas pesquisas (MORAN; MASETTO; BEHRENS, 2000; MORAN, 2010; MORAN, 2005; MORAN, 2015; SANTOS, 2015). Assim, de forma geral, a evolução das tecnologias digitais de informação e comunicação (TDIC) tem transformado profundamente a sociedade e principalmente a sala de aula (FERNANDES, 2018).

Segundo Moran, Masetto e Behrens (2000) a integração das tecnologias ao ensino reflete, dentre outros, mudanças na sociedade, cada vez mais tecnológica, e da observação de que as aulas convencionais estão ultrapassadas. Com efeito, o ensino por meio da tecnologia configura apoio, o meio e não o fim, permitindo realizar atividades de aprendizagem diferenciadas (MORAN, 2005) e impõe reflexões sobre a necessidade de repensar os processos de organização de currículos, metodologias, tempos e espaços (MORAN, 2015). Obviamente que esse procedimento é distinto entre as áreas do conhecimento, já que currículos e metodologias refletem as dinâmicas próprias de cada área.

No estudo do espaço geográfico, objeto principal da Geografia, são observados avanços tecnológicos significativos decorrente da revolução técnico-científica informacional. Nesse sentido, destaca-se a apresentação de diversos sistemas de coleta, disponibilização e processamento de imagens orbitais e de dados vetoriais, denominadas geotecnologias.

Segundo Santos $(2015,28)$ “as geotecnologias correspondem ao conjunto de tecnologias, técnicas e ferramentas computacionais, cujo objetivo é obter informações sobre a superfície terrestre, bem como, representá-las em mapas, sejam eles digitais ou analógicos e gráficos ou relatórios". Esse conjunto de tecnologias "fazem parte da tendência de construção de uma infraestrutura voltada para aquisição, processamento e análise de informações sobre o espaço geográfico que busca racionalizar o processo de tomada de decisão" (MATIAS, 2005, p. 8887).

A aplicação de geotecnologias ao ensino está amplamente difundida, em diversas abordagens (GATRELL, 2004; SÁNCHEZ, 2009; WHITAKER, 2011; KERSKI; DEMIRCI; MILSON, 2013; KERSKI, 2015; HONG, 2014; SOUSA; JORDÃO, 2015; PEREIRA; DINIZ, 2016; BRULÉ; BAILLY, 2018). Desse modo, Sánchez (2009) argumenta que o uso das geotecnologias no contexto escolar auxilia na cultura digital do cidadão do século XXI e Kerski (2015) afirma que muitas ferramentas e conjuntos de dados que antes eram restritos a especialistas estão agora disponíveis ao público em geral.

Adicionalmente, Sousa e Jordão (2015) aplicaram geotecnologias ao ensino da Geografia na Educação Básica e ao permitir ao aluno explorar e interagir com a informação geográfica, concluíram que as aulas de Geografia se tornaram mais atraentes, uma vez que mapas digitais, na internet, permitem ao aluno entender a complexidade das relações espaciais. Nesse sentido, Pereira e Diniz (2016) afirmam que o desenvolvimento das interfaces cada vez mais amigáveis entre usuário-software tornam o seu uso atrativo, e se aplicados corretamente, podem fornecer importantes contribuições ao ensino.

Apesar da importância das geotecnologias e das inúmeras aplicações, Florenzano, Lima e Moraes (2011) e Aguiar (2013) chamam a atenção para o fato de que a disseminação do uso das geotecnologias como recurso didático passa pela qualificação adequada dos 
professores ainda na graduação. Nesse sentido, Kerski, Demirci e Milson (2013) pesquisaram escolas de 33 países e revelaram que o uso do SIG permanece pequeno no Ensino Médio, ainda que os dados abertos e serviços de mapas baseados na web possam causar um aumento significativo na participação do número de escolas, educadores e estudantes usuários de geotecnologias e SIG. Conforme Hong (2014) após um treinamento de uso do SIG baseado na web para professores do ensino médio da Georgia (EUA) apenas $20 \%$ dos participantes o implementaram em sala de aula.

Além da falta de capacitação para geotecnologias na formação dos professores, outro aspecto que inviabiliza a disseminação das geotecnologias no ensino formal no Brasil diz respeito a falta de recursos didáticos inovadores nas escolas. Outros fatores são apresentados por Castanho, Marlenko e Natenzon (2013, p. 24), que destacam a "infraestrutura inadequada, carga horária escolar reduzida da disciplina de Geografia, inexistência de materiais complementares, como mapas, atlas, globos, entre outros equipamentos, e até mesmo livros didáticos com equívocos ou com informações incompletas". Além disso, Maciel (2017) argumenta que resistências pelos professores às mudanças observadas, resultam das dificuldades de acesso ao equipamento, carga horária excessiva dos professores e elevado número de alunos por turma, obstáculos que são reforçados pela falta de promoção de políticas educacionais.

A experiência em escolas públicas da cidade de Goiânia e Aparecida de Goiânia, casos mais conhecidos (SANTOS et al., 2018; SANTOS, 2018), revelou que muitos laboratórios de informática foram instalados mas, devido à falta de manutenção, muitos estão inativos. No entanto a tecnologia através da web pode ser alternativa para que estudantes explorem ferramentas de análise espacial a partir do próprio telefone móvel ou mesmo de suas residências.

Entretanto, é preciso avaliar que muitos estudantes não têm acesso a internet, pois apesar do crescente uso no Brasil é utópico e inadequado pensar que essa tecnologia chegou para todos. Isso ocorre, segundo o Comitê Gestor da Internet no Brasil (2016), pois persiste inúmeros desafios no que se refere a infraestrutura tecnológica, como por exemplo, na insuficiência de equipamentos para todos os estudantes, as limitações da conexão à Internet, assistência técnica e manutenção dos recursos TIC.

\section{METODOLOGIA}

Dentre as diversas plataformas de dados geográficos existentes, o LAPIG Maps destaca-se por oferecer cerca de 10.000 dados geográficos para todo o Brasil com metadados uniformizados e diversas ferramentas que facilitam o acesso, a análise e aquisição de dados em diferentes níveis geográficos e escalas. Neste ambiente é possível ainda, mesmo sem fazer download, realizar diversas análises espaciais.

A Plataforma LAPIG Maps foi desenvolvida ao longo das últimas três décadas. Desde 1995 o grupo de pesquisa do LAPIG vem buscando implementar ferramentas que melhorem o acesso e o manuseio da informação geográfica para diferentes públicos. De início os dados disponibilizados eram predominantemente sobre o bioma Cerrado mas na 
última década esses dados tem abrangido os demais biomas do país. Esse fato constitui uma das suas mais importantes missões em relação a produção e disponibilização de dados: todos os dados gerados com recurso público devem ser disponibilizados de maneira fácil e com credibilidade.

A Plataforma vem sendo aprimorada visando a geração de dados cartográficos e o desenvolvimento contínuo de ferramentas on line que permitam ao usuário, com níveis de conhecimento variando do básico ao avançado, analisar os ambientes físicos, bióticos e antrópicos (SILVA et al., 2017). A figura 1 mostra o ambiente do Mapa Interativo com destaque para a opção adicionar camadas de acesso aos dados, download e para a ferramenta de Inteligência Geográfica.

Figura 1 - Ambiente da Plataforma LAPIG-Maps

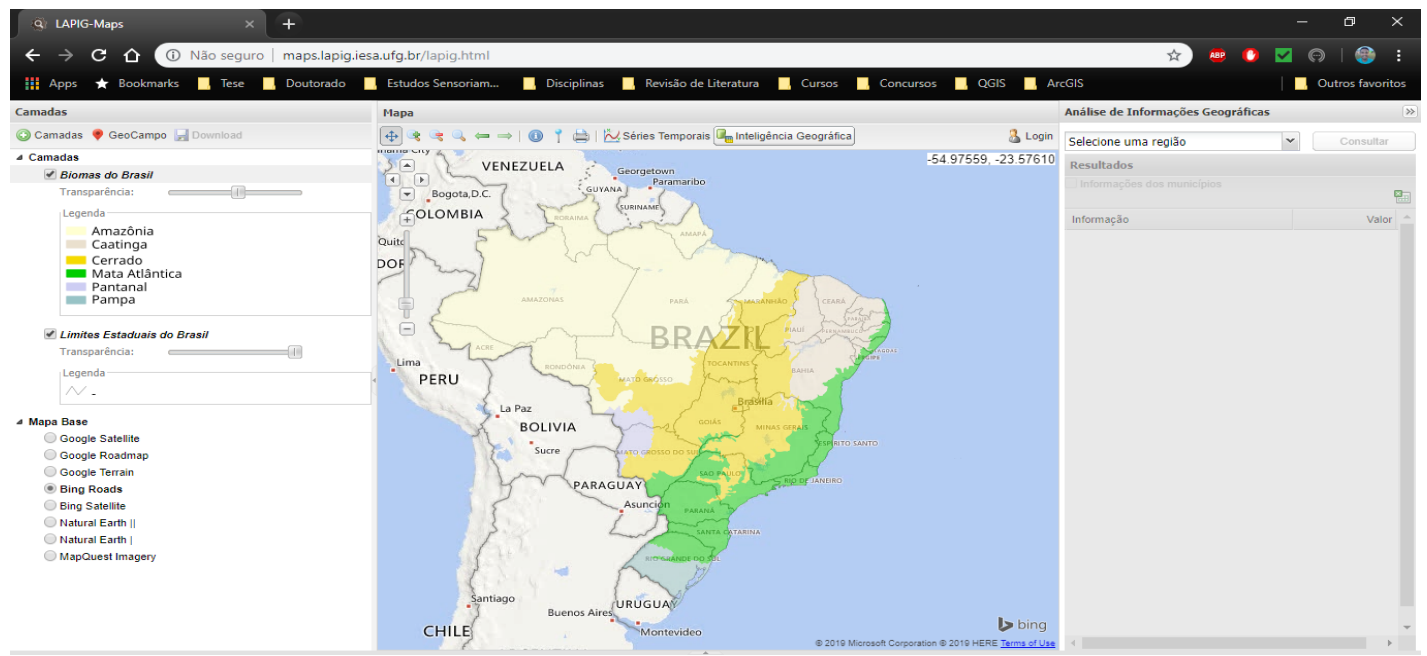

Fonte: Portal LAPIG http:/ / maps.lapig.iesa.ufg.br/lapig.html

Org.: os autores

Visando contribuir com o ensino de Geografia foram selecionados os temas desmatamento, conflitos de uso e monoculturas, trabalhados por meio dos conceitos geográficos: paisagem, território e região, expressando recorte territoriais representados, respectivamente pelo bioma Cerrado, o estado de Goiás e o recorte do MATOPIBA ${ }^{1}$ (Fig. 2).

Figura 2 - Procedimento Metodológico adotado.

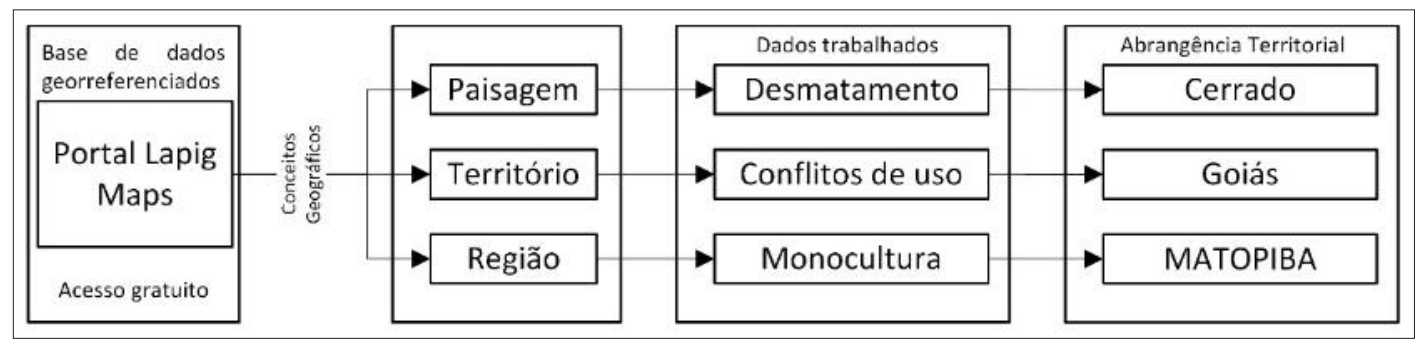

Fonte: os autores

1 Denominação dada ao conjunto de áreas que engloba de modo parcial os estados do Maranhão (MA), Piauí (PI) e Bahia (BA), e de forma total o estado do Tocantins (TO). O MATOPIBA localiza-se majoritariamente em áreas do Bioma Cerrado, sendo considerada uma grande fronteira agrícola nacional (BUAINAIN; GARCIA; VIEIRA FILHO, 2017). 
A seleção dos conceitos deu-se pela capacidade conceitual de cada termo em expressar percepções ou perspectivas de análise do espaço geográfico. Cavalcanti (2006), por sua vez, destaca que o desenvolvimento de habilidades para analisar de maneira crítica o espaço geográfico só pode ser construído através da formação de conceitos pelo aluno. O conceito é aqui compreendido como uma operação cognitiva, situado na dinâmica das funções psicológicas elementares somadas às funções psicológicas superiores que culminam na palavra, que, por usa vez, tem significado no mundo e no sujeito durante todo o processo de desenvolvimento intelectual (SOUZA; SILVA, 2015).

Nessa perspectiva de ensinar por conceitos, são necessárias ações além da transferência de conhecimentos por parte do professor, e da reprodução de conteúdo por parte do aluno. É considerar o aluno sujeito na construção do seu conhecimento e o professor aquele que problematiza os conteúdos geográficos, que cria situações para o aluno formular hipóteses, que usa de arsenais metodológicos e procedimentais para acessar conteúdos geográficos para desenvolver o pensamento geográfico. Parte-se, então, do princípio de que a aprendizagem dos alunos decorre do papel exercido pelo professor na construção de conhecimento, utilizando materiais e ferramentas que, aqui nesse trabalho, são representadas pelo portal LAPIG Maps.

Nesse processo de ensinar através de conceitos, destaca-se a necessidade de diversas ações cognitivas apontadas por Florenzano (2011, p. 121) ao deixar claro que "a partir da análise e interpretação (ao falar de interpretação, deve-se compreender os dados extraídos) de imagens de sensores remotos, os conceitos geográficos de lugar, localização, interação homem/meio, região, movimento (dinâmica) podem ser articulados". Portanto, este trabalho associa-se à ideia do 'percebido' e do 'natural', relacionando-os ao conceito de paisagem; o conflito é relacionado ao conceito de território; a região associa-se aos recortes de abrangência regional.

Os próximos procedimentos envolveram a seleção dos dados para cada tema e a definição do modo de trabalho levantada para cada eixo temático utilizado, tal como a temporalidade possível das análises e formas de representação dos dados. Foi realizada ainda uma exploração do potencial do portal, com vistas a identificar formas de trabalho, pensadas como contribuição para a Geografia Escolar e possíveis fragilidades.

\section{RESULTADOS}

Ao trabalhar o conceito de paisagem, principalmente no que diz respeito às suas características ambientais e/ou naturais selecionou-se os dados referentes aos "alertas de desmatamento nos municípios do Cerrado"2. Tal dado vem sendo sistematicamente produzido pelo LAPIG, por meio de imagens do satélite MODIS e validadas com imagens dos satélites LANDSAT e CBERS. A escala utilizada é de 1:250.000 e o recorte temporal compreende os anos de 2003 a 2016. Esse dado compreende uma série temporal que pode

2 Os dados utilizados neste trabalho se encontram na área destinada a busca por termos chave dentro da opção 'camadas' no portal LAPIG. 
ser visualizada em qualquer um dos anos específicos e/ ou pode ser exibida uma animação demonstrando as modificações ano a ano (Fig. 3).

Figura 3 - Alertas de desmatamento do bioma Cerrado, anos de 2003, 2009 e 2016.

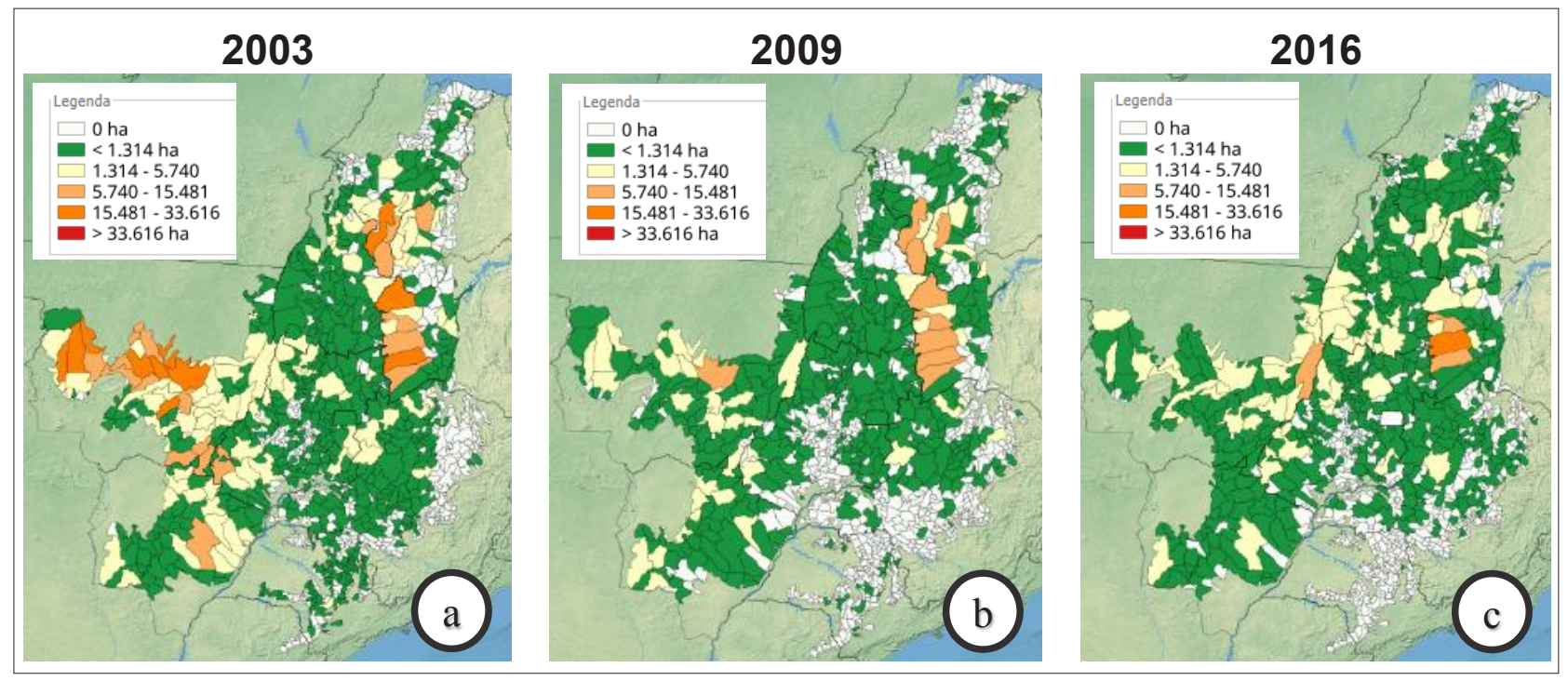

Fonte: Portal LAPIG

Org.: os autores.

Assim esses dados podem ser utilizados nas aulas de geografia para o estudo dos biomas, da vegetação (por estados ou municípios dentro de um bioma específico), dos desmatamentos e temas correlatos como o avanço das monoculturas e da pecuária, o desaparecimento da fauna, as queimadas e as alterações no ciclo hidrológico.

Ao trabalhar o conceito de território, principalmente no que diz respeito a questões de conflito, em especial aqueles de uso e ocupação do solo, selecionou-se os dados referentes ao "uso do solo de Goiás" com escala de 1:250.000, recorte temporal focado no ano de 2004, produzido pelo Sistema Estadual de Geoinformação - SIEG. Outros dados utilizados enfatizam as "Unidades de Conservação de Uso Sustentável de Goiás” com escala aproximada de 1:1. 000.000, recorte temporal em 2006 também produzido pelo SIEG. Por último foi utilizado o "Índice de Desenvolvimento Humano Municipal" - IDH, calculado pela média geométrica dos índices das dimensões de Renda, Educação e Longevidade e disponibilizados para os últimos três Censos Demográficos do IBGE - 1991, 2000 e 2010. A escala aproximada é de 1:250.000 (Fig. 4).

As imagens mostram o mesmo cenário, no entanto apresentam informações distintas. Dessa forma, cria-se no aluno a capacidade fazer a leitura espacial dos fenômenos e entender a complexidade do espaço geográfico. Ao contrapor os dados, pode-se fazer leituras espaciais do um avanço das áreas de pastagem e agricultura nas unidades de uso sustentável do estado, por exemplo, e o IDH desses municípios. 
Figura 4 - Uso do solo em Goiás, unidades de conservação de uso sustentável e IDH municipal.
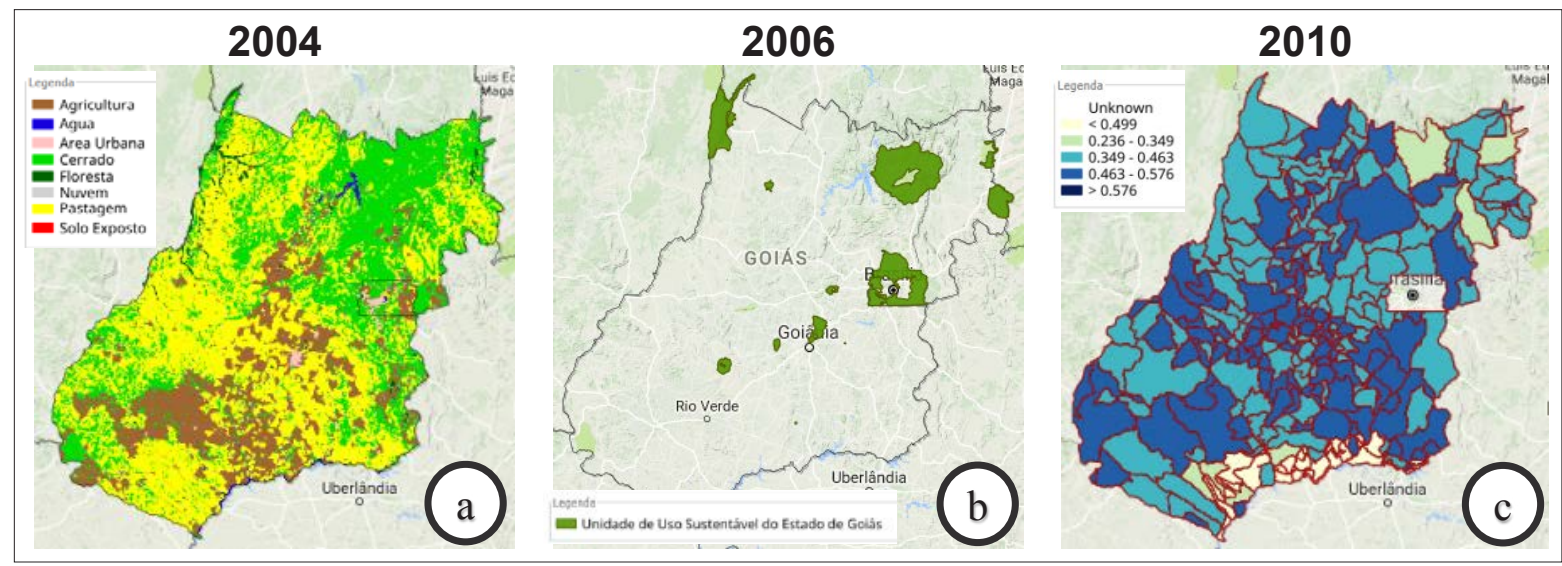

Fonte: Portal LAPIG

Org.: os autores.

Assim esses dados podem ser utilizados nas aulas de geografia para o estudo de questões territoriais, tais como uso e apropriação dos solos, tendências de modificação do uso (com mapas anuais de uso do solo), o avanço da fronteira agrícola sobre comunidades tradicionais, terras indígenas, conflitos por terra e por água, além dos fundiários, o IDH e sua composição, bem como temas correlatos como a preservação de áreas de interesse ecológico em conflito.

Ao trabalhar o conceito de região, principalmente no que diz respeito a questões de apropriação regional do espaço, em especial, aquelas realizadas pelas grandes monoculturas, selecionou-se os dados referentes ao "Produção de Soja por Municípios do MATOPIBA", com dados em toneladas, no período de 2000 a 2016, conforme dados censitários do IBGE. A escala é de1:250.000 com recorte temporal entre os anos 2000 e 2010 (Fig. 5).

Figura 5 - Produção de soja por municípios da região do MATOPIBA, anos 2000, 2006 e 2016.
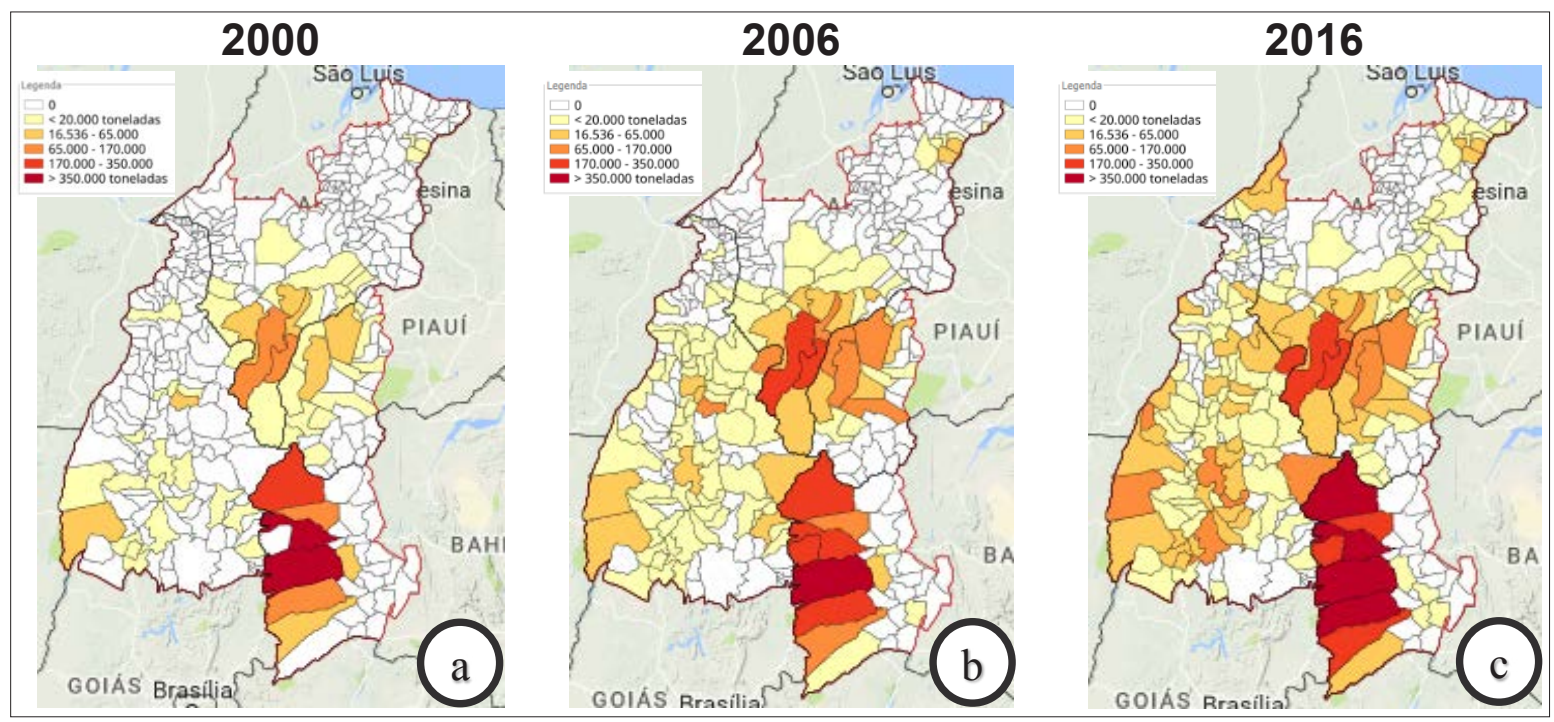

Fonte: Portal LAPIG

Org.: os autores. 
Assim esses dados podem ser utilizados nas aulas de geografia para o estudo de questões regionais, naquilo que diz respeito a apropriação da natureza tanto pelas monoculturas em outras regiões do país. Podem ser levantadas questões acerca dos motivos, benefícios e impactos ambientais e sociais da implantação de monoculturas.

\section{CONSIDERAÇÕES FINAIS}

No contexto da Geografia Escolar, entendida por Cavalcanti (2006, p. 34) como “[...] um conjunto de instrumentos simbólicos, conceitos, categorias, teorias, dados, informações e procedimentos sobre o espaço geográfico", é importante contribuir para a formação de indivíduos com habilidades de compreensão do espaço geográfico em sua conjuntura física e social. A cartografia tem sido a principal ferramenta para o geógrafo analisar o espaço e, com a evolução tecnológica, destacam-se os meios de veiculação da informação, principalmente on line. Nesse sentido, a cartografia também tem incorporado a tecnologia em suas técnicas de elaboração e disponibilização de dados através das Geotecnologias.

As inovações mais recentes da Geotecnologia possibilitaram um profundo avanço na disponibilização de conteúdo, com o surgimento dos ambientes de SIGs on line. Esses ambientes, quando bem estruturados, permitem a aquisição, e a manipulação da informação de vários ambientes do espaço geográfico de forma segura e remota. No que concerne, ao processo de formação de professores, este tem incorporado de maneira muito singela o preparo dos futuros licenciados para lidar com esses ambientes.

A inserção das Geotecnologias na formação dos professores é fundamental ao permitir aos professores maiores possibilidades no processo de formação de seus alunos, aliando, dentre outras, teoria, prática e conhecimento do mundo real de maneira dinâmica em diferentes escalas de análise.

A Plataforma LAPIG Maps possui grande potencial para o desenvolvimento de atividades, possibilitando a visualização de informações censitárias, vetoriais e imagens da superfície. Informações vetoriais podem ser sobrepostas em imagens de satélite e há possibilidade de visualização animada (dinâmica) de dados de séries temporais de múltiplos anos, além de permitir recortes específicos (municípios, estados, biomas).

No entanto, por não ser inicialmente uma plataforma voltada para o público dos ensinos fundamental e médio, ainda precisa ser melhor adaptada, visto que dificilmente um aluno conseguirá utilizar todas as possibilidades do portal sem o auxílio do professor que domine o arcabouço teórico-metodológico da geotecnologia. Este deve ser capaz de realizar a transposição didáticas dos conhecimentos e aplicá-la na construção de conceitos geográficos em sala de aula.

Destaca-se ainda que as orientações apontadas neste artigo para se trabalhar com os conceitos não pretendem contemplar todos os passos metodológicos para o ensino nessa perspectiva. As informações existentes no portal LAPIG Maps constituem um ponto de partida para o ensino dos conceitos destacados nesse trabalho, os quais necessitam de planejamento detalhado dos diversos procedimentos didáticos envolvidos. Os exemplos 
aqui apresentados, no entanto, evidenciam como problematizar diversos fenômenos geográficos, permitindo ao professor ampliar suas condições de sistematização desses fenômenos, uma vez que problematizar e sistematizar são importantes etapas da metodologia de ensinar por conceitos.

\section{REFERÊNCIAS}

AGUIAR, P.F. Geotecnologias como metodologias aplicadas ao ensino de geografia: uma tentativa de integração. Geosaberes, v. 4, n. 8, p. 54-66, 2013.

BRULÉ, E.; BAILLY, G. Taking into Account Sensory Knowledge: the Case of Geo-technologies for Children with Visual Impairments. In: ACM CHI', 18, 2018, Montreal. Anais... p. 2-12.

BUAINAIN, A.M.; GARCIA, J.R.; VIEIRA FILHO, J.E. Dinâmica econômica e da agropecuária no MATOPIBA. Rio de Janeiro: Ipea, 2017. (Série: textos para discussão)

CASTANHO, R.B.; MARLENKO, N.; NATENZON, C.E. Aa Geotecnologias e o ensino universitário: comparações metodológicas da disciplina de Sensoriamento Remoto. Revista Brasileira de Educação em Geografia, v. 3, n. 5, p.21-38, jan./jun. 2013.

CAVALCANTI, L.S. Bases teórico-metodológicas da Geografia: uma referência para a formação e a prática de ensino. In: ROSA, Dalva E. Gonçalves et al. Formação de professores: concepções e práticas em Geografia. Goiânia: E.V., 2006.

CASTRO, W.S.; FERREIRA, M.E. Bases de dados geográficas no Brasil: formatos, acessibilidade e aplicações. Ateliê Geográfico, v. 6, n. 1, p. 92-122, abr. 2012.

FITZ, P.R. Geoprocessamento sem complicação. São Paulo: Oficina de Textos, 2008a.

. Cartografia básica. São Paulo: Oficina de Textos, 2008b.

Geografia Tecnológica: uma nova maneira de pensar a Geografia. In: ENCONTRO NACIONAL DOS GEÓGRAFOS. 16. 2010. Porto Alegre. Anais ... p. 21-33

FERNANDES, L.C.B.E. Possíveis TDIC utilizadas no processo de ensino da geografia. CIET: EnPED, [S.1.], maio 2018.

FLORENZANO, T.G. Sensoriamento remoto como recurso didático. In: . Iniciação em Sensoriamento Remoto. 3. ed. ampl. e atual. São Paulo: Oficina de Textos, 2011.

; LIMA, S.F.S.; MORAES, E.C. Formação de professores em geotecnologia por meio de ensino a distância. Educar em Revista, n. 40, p. 69-84, abr./jun. 2011.

GATRELL, J.D. Making Room: Integrating Geo-technologies into Teacher Education. Journal of Geography, v. 103, p. 18-25, 2004.

HONG, J.E., Promoting Teacher Adoption of GIS Using Teacher-Centered and Teacher-Friendly Design. J. Geogr., v. 113, n. 4, p. 139-150, 2014. DOI: 10.1080/00221341.2013.872171.

KERSKI, J.J. Geo-awareness, Geo-enablement, Geotechnologies, Citizen Science, and Storytelling: Geography on the World Stage. Geography Compass, v. 9, n. 1, p. 1-18, 2015.

; DEMIRCI, A; MILSON A.J. The Global Landscape of GIS in Secondary Education. J. Geogr., v. 112, n. 6, p. 232-247, 2013.

MACIEL, O.M.G. As TIG no ensino de Geografia: concepções, usos escolares e suas condicionantes. 2017. 415 f. Tese (Doutorado em Geografia) - Faculdade de Letras da Universidade de Coimbra, Portugal. Disponível em: http:/ /hdl.handle.net/10316/32362. Acesso em: 22 ago. 2019.

MATIAS, L. F. Por uma economia política das geotecnologias. In: ENCONTRO DE GEÓGRAFOS DA AMÉRICA LATINA, 10. 2005, São Paulo. Anais... São Paulo: USP, 2005. p. 8879-8899. 
MORAN, J.M. Ensino e aprendizagem inovadores com tecnologias. Informática na Educação: Teoria \& Prática, Porto Alegre, v. 3, n.1, p.1-18, 2000.

Integração das Tecnologias na Educação. In: ALMEIDA, M.E.B. de; MORAN, J.M. Salto para o Futuro. Brasília: SEED, 2005. Disponível em: http://www.pucrs.br/ciencias/viali/tic_literatura/livros/ Salto_tecnologias.pdf. Acesso em: 23 ago. 2019.

Ensino e aprendizagem inovadores com tecnologias audiovisuais e telemáticas. In: MORAN, José Manuel. MASETTO, M.T.; BEHRENS, M.A. Novas tecnologias e mediação pedagógica. 17.ed. Campinas: Papirus, 2010.

Mudando a educação com metodologias ativas. 2015. Coleção Mídias Contemporâneas. Convergências Midiáticas, Educação e Cidadania: aproximações jovens. V. 2. Disponível em: http:// www2.eca.usp.br/moran/wp-content/uploads/2013/12/mudando_moran.pdf Acesso em: 22 ago. 2019. 2000.

; MASETTO, M.T.; BEHRENS, M.A. Novas tecnologias e mediação pedagógica. Campinas: Papirus,

COMITÊ GESTOR DA INTERNET NO BRASIL. Educação e tecnologias no Brasil: um estudo de caso longitudinal sobre o uso das tecnologias de informação e comunicação em 12 escolas públicas / Núcleo de Informação e coordenação do Ponto BR. -- 1. ed. -- São Paulo : Comitê Gestor da Internet no Brasil, 2016. Disponível em: https://cetic.br/media/docs/publicacoes/7/EstudoSetorialNICbr_TIC-Educacao.pdf. Acesso em: 22 ago. 2019.

SANTOS, A.M. Experiência pedagógica em geotecnologias para um curso de engenharia na Amazônia Ocidental. In: SEMINÁRIO DE EDUCAÇÃO, 8, 2015, Rolim de Moura. Anais.... p. 1-12.

; MATINELI, G.V; VILARINO, M.; BARROS, J.P. "A Universidade vai à escola": Relatos de uma Experiência de Extensão Universitária em Cartografia. Revista de Cultura e Extensão USP, Vol. 19, p. 91105, 2018. Disponível em: https:/ / doi.org/10.11606/issn.2316-9060.v19i0p91-105. Acesso em: 15 jun. 2019.

Educação para o trânsito na escola: relato de uma experiência pedagógica a partir da extensão universitária. Revista Diálogos, v. 22, nº 1, p. 19-34, 2018. Disponível em: https://portalrevistas.ucb.br/ index.php/RDL/article/view/9491/6100. Acesso em: 18 jun. 2019.

SILVA, E.V.; RODRIGUEZ, J.M.M. O ensino da geografia física: práticas pedagógicas e perspectivas interdisciplinares. Revista Equador, v. 3, n. 2, p. 38-50, 2014.

SILVA, W.C; FERREIRA, M.E.F; TEIXEIRA, L.M.S et al. Plataforma livre e interativa de mapas para a gestão territorial e ambiental do bioma Cerrado. Rev Bras. Cartogr., v.69, n. 8, p. 1598-1609, 2017.

SOUZA, V.C.; SILVA, T.A. Ensinar Geografia pela construção de conceitos. In: Xosé Carlos Macía Acre; Francisco Rodríguez Lestegás; Francisco Xosé Armas Quintá. (Org.). Ensinar Geografia, realidades e propostas no Brasil e Galiza. Santiago de Compostela: Andavira, 2015.

SOUSA, I. B.; JORDÃO, B.G.F. Geotecnologias como recursos didáticos em apoio ao ensino de cartografia nas aulas de geografia do ensino básico. Caminhos de Geografia, v. 16, n. 53, p. 150-163, 2015.

PEREIRA, V.H.C.; DINIZ, M.T.M. Geotecnologias e Ensino de Geografia: algumas aplicações práticas. Cad. Geogr., v.26, n.47, p. 23-34, 2016.

SÁNCHEZ, E. Innovative Teaching/Learning with Geotechnologies in Secondary Education. In: IFIP TC 3 WORLD CONFERENCE ON COMPUTERS IN EDUCATION, 9, 2009, Bento Gonçalves. Anais... p. 65-74.

WHITAKER, D. Using Geographic Information Systems in Science Classrooms. Educar em Revista, n. 40, p. 51-68, abr./jun. 2011.

Data de submissão: 22/fev./2019

Data de aceite: 08/jun./2019 